\title{
Cystinosis
}

\section{INTRACELLULAR CYSTINE DEPLETION BY AMINOTHIOLS IN VITRO AND IN VIVO}

\author{
Jess G. Thoene, Robert G. Oshmma, John C. Crawhall, Davm L. Olson, \\ and JERrY A. SCHNEmER \\ From the Department of Pediatrics, University of California, San Diego, \\ La Jolla, California 92093 and, the Division of Nephrology, University of \\ Southern California, School of Medicine, Los Angeles, California 90033
}

\begin{abstract}
A в S T R A C T Certain aminothiols rapidly deplete cultured cystinotic skin fibroblasts of their abnormally high free (nonprotein) cystine pool. The free cystine content of these cells is reduced by over $90 \%$ in $1 \mathrm{~h}$ with $0.1 \mathrm{mM}$ cysteamine. This is more rapid than previously known methods of removing free cystine from cystinotic fibroblasts. The disulfide, cystamine, is also able to deplete cystinotic cells of free cystine.

A patient with nephropathic cystinosis and end-stage renal disease was treated with cysteamine, both intravenously and orally. Both methods of administration rapidly lowered the free cystine content of the patient's peripheral leukocytes.

Study of the patient's urinary sulfur excretion did not conclusively determine the effect of this therapy on the total body cystine pool. Her renal status remained at end stage after 1 mo of oral cysteamine, when an episode of grand mal seizures prompted cessation of the study. Determination of the proper place of aminothiol therapy in this disease will depend upon further clinical trial with patients whose kidney function has not deteriorated to the point of irreversible change, accompanied by careful monitoring of plasma aminothiol levels.
\end{abstract}

\section{INTRODUCTION}

Nephropathic cystinosis is an inherited error of cystine metabolism characterized by autosomal recessive trans-

This work was presented in part at The Society for Pediatric Research, April 1975, and The American Society for Clinical Investigation, May 1975.

Dr. Thoene is the recipient of U. S. Public Health Service Research Fellowship 1-F22-AM-00321 from the National Institute of Arthritis, Metabolism and Digestive Diseases, and is also a Lalor Foundation Fellow. Dr. Oshima is the recipient of a U. S. Public Health Service Research Fellowship 1-F22-GM-04023 from the National Institute of General Medical Sciences.

Received for publication 18 September 1975 and in revised form 26 February 1976. mission, free (nonprotein) cystine accumulation within lysosomes, renal tubular dysfunction, and progressive glomerular insufficiency leading to end-stage renal failure in the first decade of life. In spite of extensive investigations $(1,2)$, the primary defect leading to cystine accumulation and renal failure is unknown.

The accumulation of free cystine in fibroblasts cultured from cystinotic patients has provided a convenient in vitro test system for the evaluation of methods of lowering the intracellular nonprotein cystine content of these cells. Effective methods include growth in a lowcystine medium (3), treatment with dithiothreitol $(\mathrm{DTT})^{1}(4,5)$, and treatment with ascorbic acid (6). None of these methods has been proved effective clinically, although DTT treatment has been shown to lower the leukocyte nonprotein cystine content in vivo (7).

This report shows the effectiveness of certain aminothiols in producing a rapid and complete depletion of nonprotein cystine from cystinotic fibroblasts without producing apparent morphological signs of cytotoxicity. The cystine released is utilized by the cell for GSH synthesis. A series of structural analogues of the aminothiol, cysteamine (2-aminoethanethiol), have been investigated and allow some tentative conclusions on the relative effectiveness of these compounds in depleting cystine from cystinotic fibroblasts. A mechanism is proposed as to how these compounds produce cystine depletion without themselves accumulating.

A patient with nephropathic cystinosis and end-stage renal failure was treated with cysteamine, both intravenously and orally. Both modes of administration produced marked lowering of the peripheral leukocyte nonprotein cystine content. Renal function remained unchanged during a 2 -mo treatment.

\footnotetext{
1 Abbreviations used in this paper: DTT, dithiothreitol; GSH-NEM, $N$-ethylmaleimide adduct of glutathione ; NEM, $N$-ethylmaleimide.
} 


\section{METHODS}

Cell culture and biochemistry. Skin fibroblasts from patients with nephropathic cystinosis and normal individuals were established in culture and maintained as previously described $(8,9)$. $7-9 \times 10^{5}$ cells were plated in $100-\mathrm{mm}$ Falcon Petri dishes (Falcon Plastics, Div. of BioQuest, Oxnard, Calif.) and harvested $72 \mathrm{~h}$ later while in logphase growth. A modified Ham's F12 medium was used for complete (cystine-containing) medium (8). Cystine-deficient medium was the same medium with cystine omitted. Both were supplemented with $10 \%$ fetal bovine serum. When used to supplement the cystine-deficient medium, the fetal bovine serum was dialyzed.

Unradiolabeled cells were harvested by trypsinization (8) after being washed three times in phosphate-buffered saline (10) at $4^{\circ} \mathrm{C}$. Cell number was determined with a Coulter Counter, model ZBI (Coulter Electronics Inc., Hialeah, Fla.). Protein was determined colorimetrically (11) with bovine serum albumin as the standard. The intracellular nonprotein cystine content of fibroblasts and leukocytes was measured by a cystine-binding protein assay (8). L- $\left[{ }^{35} \mathrm{~S}\right]-$ Cystine (sp act $395 \mathrm{mCi} / \mathrm{mmol}$ and $23.2 \mathrm{Ci} / \mathrm{mmol}$ ) was obtained from Amersham/Searle Corp. (Arlington Heights, III.) and New England Nuclear (Boston, Mass.), respectively. Purity of labeled cystine was greater than $98 \%$ when tested by high-voltage electrophoresis, followed by radiochromatogram scan (see below). Cysteamine and its analogues were the best available grade (over 97\% purity) and obtained from either Calbiochem (San Diego, Calif.) or Aldrich Chemical Co., Inc. (Milwaukee, Wis.). Omnifluor was purchased from New England Nuclear.

In studies with labeled material, Petri dishes of fibroblasts in log-phase growth were washed four times in phosphate-buffered saline at $4^{\circ} \mathrm{C}$ and harvested by direct freezing of the cells in the culture dish on a dry ice-ethanol bath in the presence of $5 \mathrm{mM} N$-ethylmaleimide (NEM) in $10 \mathrm{mM}$ potassium phosphate buffer at $\mathrm{pH}$ 7.4. The cells were then thawed briefly at $60^{\circ} \mathrm{C}$ and detached from the surface with a rubber scraper at $25^{\circ} \mathrm{C}$. The initial cell lysate, plus a $2-\mathrm{ml} \mathrm{H}_{2} \mathrm{O}$ wash, were combined and lyophilized. The residue was dissolved in $400 \mu 1$ of $3 \%$ sulfosalicylic acid, and the acid-soluble fraction was analyzed by high-voltage electrophoresis on paper.

High-voltage electrophoresis on paper was performed on a Camag high-voltage electrophoresis system (Camag Inc., New Berlin, Wis.). Known standards included taurine, cysteic acid, GSH-NEM, cysteine-NEM, cystine, methionine, cysteamine-NEM, the mixed disulfide of cysteamine and cysteine, and cystamine. These standards were added to the samples, and the mixtures were run in $6 \%$ formic acid buffer, $\mathrm{pH} 1.7$, at $97 \mathrm{~V} / \mathrm{cm}$. The paper was dried, and the spots were identified with ninhydrin (12). The areas of radioactivity were localized with a Packard radiochromatogram scanner, model 7201 (Packard Instrument Co., Inc., Downers Grove, IIl.), and quantitated by cutting out the positive areas and counting in Omnifluor, $4 \mathrm{~g} / \mathrm{liter}$ of toluene, in a Beckman liquid scintillation system (Beckman Instruments, Inc., Fullerton, Calif.). Counting efficiency for ${ }^{35} \mathrm{~S}$ was $98 \%$.

Granule-rich fractions from cystinotic fibroblasts were prepared by disruption of cells by sonication in $0.25 \mathrm{M}$ sucrose. The nuclei and membrane fragments were removed by centrifugation at $1,000 \mathrm{~g}$ for $10 \mathrm{~min}$, and the granular fraction was obtained by centrifugation at $27,000 \mathrm{~g}$ for 30 min with resuspension in $0.25 \mathrm{M}$ sucrose in $10 \mathrm{mM}$ potassium phosphate buffer, $\mathrm{pH} 7.4$ (13). To determine the cystine depletion effect of various compounds on cystinotic granules, portions of the granule suspension were added to tubes containing the test reagents and incubated at $25^{\circ} \mathrm{C}$ for $30 \mathrm{~min}$. Granules from $100 \mu \mathrm{l}$ of the incubation mixture were recovered by centrifugation at $27,000 \mathrm{~g}$ for $20 \mathrm{~min}$, sonicated in the presence of $5 \mathrm{mM} \mathrm{NEM}$ in $10 \mathrm{mM}$ potassium phosphate buffer, $\mathrm{pH} 7.4$, and precipitated with $3 \%$ sulfosalicylic acid. Cystine was measured with a cystinebinding protein assay (8). Urinary sulfur and sulfate were determined as previously described (14). Urinary and plasma amino acids were determined with a Durrum 500 amino acid analyzer (Durrum Instrument Corp., Palo Alto, Calif.) (15).

Case report. A 7-yr-old white girl with nephropathic cystinosis was the fourth affected of seven siblings in this family. Three older sibs have died of renal failure due to cystinosis. Renal transplantation was refused by the parents, and a trial of cysteamine was therefore offered. Food and Drug Administration approval and informed consent were obtained before the drug trial.

The patient was a small, pale child with a weight of $17.6 \mathrm{~kg}(<3$ percentile) and height of $107 \mathrm{~cm} \quad(<3$ percentile). Slight frontal bossing and uremic breath were the only other positive physical findings. Her pulse was 85 , her respiration 16 , and her blood pressure $114 / 74$.

Initial laboratory values included a blood urea nitrogen of $145 \mathrm{mg} / 100 \mathrm{ml}$, serum creatinine of $6.5 \mathrm{mg} / 100 \mathrm{ml}$, creatinine clearance of $8.7 \mathrm{ml} / \mathrm{min}$ per $1.73 \mathrm{~m}^{2}$, calcium of 9.9 $\mathrm{mg} / 100 \mathrm{ml}$, phosphorus of $11.6 \mathrm{mg} / 100 \mathrm{ml}$, white blood cell count of $5,600 / \mathrm{mm}^{3}$, reticulocytes of $1.1 \%$, hemoglobin 6.7 $\mathrm{mg} / 100 \mathrm{ml}$, and a hematocrit of 20 . Serum electrolytes, liver functions, white blood cell differential, and platelet count were within normal limits. Long-bone $\mathrm{X}$-rays demonstrated minimal changes of renal osteodystrophy. Ophthalmological examination showed the typical keratopathy and retinopathy of cystinosis (16). During the study period, the patient was maintained on her previous regimen of oral aluminum hydroxide (Amphojel, Wyeth Laboratories, Div., American Home Products Corp., Philadelphia, Pa.), sodium and potassium citrate solution, vitamin $\mathrm{D}$, (dihydrotachysterol) $0.1 \mathrm{mg} /$ day, and vitamin C, $3 \mathrm{~g} /$ day.

Cysteamine for intravenous use was sterilized, lyophilized (17), tested for sterility and pyrogens, and stored at $-20^{\circ} \mathrm{C}$. It was dissolved in sterile, normal saline immediately before administration and injected over a 5 -min period. Cysteamine for oral administration was prepared in gelatin capsules and stored at room temperature in sealed jars containing dessicant. After 3 wk of storage, the compound was reacted with NEM and studied by high-voltage electrophoresis as decribed above; cysteamine-NEM was the only ninhydrinreactive spat.

\section{RESULTS}

Fibroblasts. The rate of depletion of free cystine from cystinotic fibroblasts by cysteamine and the effect of concentration are shown in Fig. 1. $90 \%$ of the original intracellular nonprotein cystine content is depleted in 1 $\mathrm{h}$ by both $1 \mathrm{mM}$ and $0.1 \mathrm{mM}$ cysteamine. $50 \%$ of the cystine depletion occurs in the first 15 min after addition of $0.1 \mathrm{mM}$ cysteamine to the culture medium. The rate of depletion caused by cysteamine compared to DTT, cystamine, and penicillamine is shown in Fig. 2. The values for DTT agree with previous studies $(4,5)$. At a concentration of $1 \mathrm{mM}$, cystamine, the disulfide of 


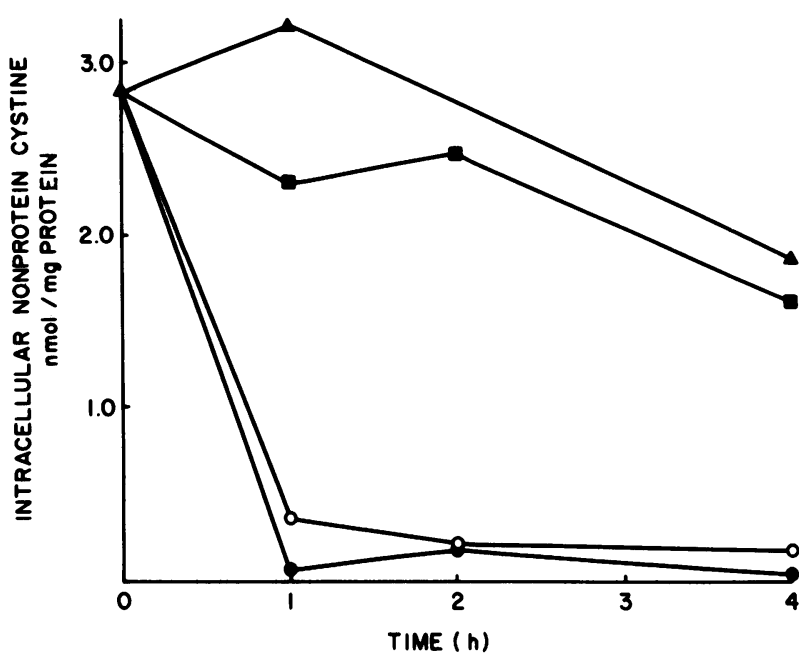

FIGURE 1 The effect of cysteamine on the intracellular nonprotein cystine content of cystinotic fibroblasts in cystinedeficient medium. $1.0 \mathrm{mM} \bullet 0.10 \mathrm{mM} \mathrm{O}, 0.01 \mathrm{mM} \square$, control $\mathbf{\Delta}$.

cysteamine, is equally as effective as cysteamine in producing intracellular nonprotein cystine depletion from cystinotic fibroblasts. However, penicillamine (D-3-mercaptovaline) produces no appreciable free cystine depletion under these conditions.

Table I lists analogues of cysteamine and their effect on the intracellular nonprotein cystine content of cystinotic cells, along with the effect of selected compounds on L-cystine in a simple cell-free chemical reaction. The dimethyl derivative, 2-dimethylaminoethanethiol, is approximately as effective as cysteamine in producing intracellular nonprotein cystine depletion at $1 \mathrm{mM}$ concentration. At these concentrations and reaction conditions, sulfhydryl compounds of similar molecular weight but possessing a hydrogen, hydroxyl, or methyl group instead of an amine in the two position do not produce cystine depletion from cystinotic fibroblasts. Both dithiols studied produced approximately $50 \%$ depletion at $1 \mathrm{~h}$. Ethanolamine, with a molecular weight similar to cysteamine but without a sulfhydryl moiety, produced no cystine depletion either in cells or in the simple chemical reaction. Cystamine, the disulfide of cysteamine, is highly effective in producing cystine depletion from cystinotic fibroblasts but ineffective in lowering the cystine concentration in a cell-free system. The monosulfide, bis(2-aminoethyl)sulfide, does not cause cystine depletion in either system.

The effect of $1 \mathrm{mM}$ cysteamine in cystine-deficient medium on cystinotic and normal fibroblasts prelabeled for $18 \mathrm{~h}$ with $\mathrm{L}-\left[{ }^{35} \mathrm{~S}\right]$ cystine is shown in Table II. A rapid drop of labeled cystine to undetectable levels occurs in the cystinotic cells, as expected from the previous experiments. The $\left[{ }^{25} \mathrm{~S}\right]$ in the cysteine pool is de- pleted to about $50 \%$ of control levels in both normal and cystinotic fibroblasts, and the amount of label in GSH falls in the normal but rises slightly in the cystinotic cells. The rise in labeled GSH could have been due to incorporation of labeled cysteine resulting from reduction of some labeled cystine released by the action of cysteamine, but the large pool of GSH would have obscured this finding. Therefore, experiments using cells depleted of GSH were undertaken.

GSH levels in both normal and cystinotic fibroblasts can be lowered to less than $10 \%$ of control by incubation in cystine-deficient medium for 20-24 h (18). Table III shows the effect of cysteamine and cystamine on cystinotic fibroblasts placed in a cystine-deficient medium for $22 \mathrm{~h}$. In Table IIIA, cystinotic cells labeled with L- $\left[{ }^{35} \mathrm{~S}\right]$ cystine for $22 \mathrm{~h}$ have been depleted of GSH by subsequent incubation in a cystine-deficient medium for $22 \mathrm{~h}$, and show about $10 \%$ of the total $\left[{ }^{25} \mathrm{~S}\right]$ label compared to those in the preceding experiments, due to loss of label during the cystine-deficient incubation. Treatment of these cells for $1 \mathrm{~h}$ with cysteamine produces a 94\% loss in label recovered as cystine, a threefold increase in label recovered as glutathione, and a twofold increase in label recovered as cysteine. These results are unchanged if the overlying medium is replaced during the 1-h cysteamine incubation or if the medium vol-

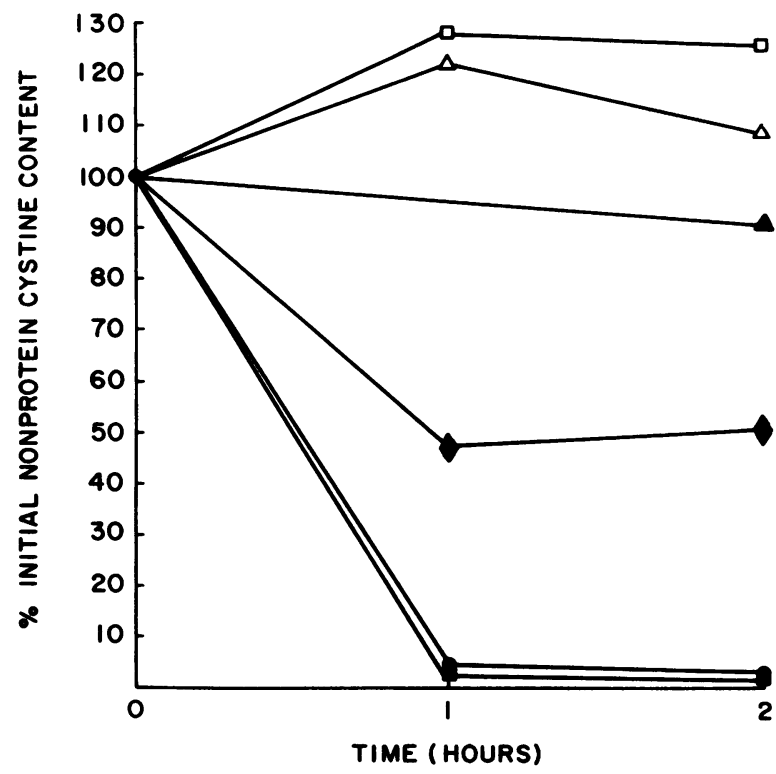

FIGURE 2 The depletion of intracellular nonprotein cystine from cystinotic fibroblasts. $1 \mathrm{mM}$ penicillamine, $\square ; 1 \mathrm{mM}$ DTT, $\bullet ; 1 \mathrm{mM}$ cystamine, $\bullet ; 1 \mathrm{mM}$ cysteamine, $\square$; controls (no addition), $\Delta, \Delta$. This figure combines the results of two experiments in different cystinotic cell lines. The initial nonprotein cystine content for open symbols was $1.5 \mathrm{nmol} / 10^{\circ}$ cells. Initial value for closed symbols was $2.8 \mathrm{nmol} / 10^{\circ}$ cells. Cystine-deficient medium was used for all experiments. 
TABLE I

Residual Cystine after Reaction in Fibroblasts and in a Cell-Free Chemical Reaction

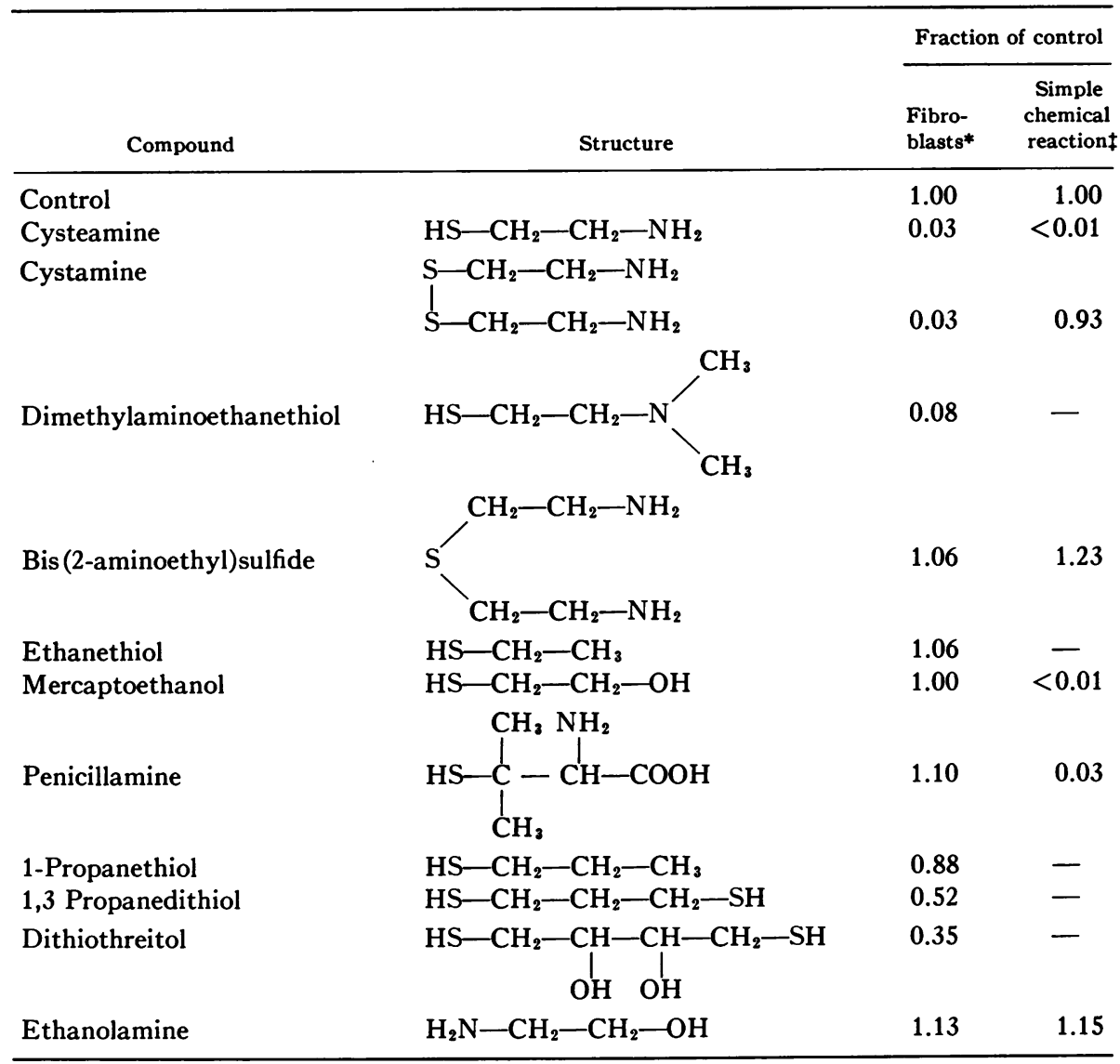

* Compounds were added to cystine-deficient medium to a final concentration of $1 \mathrm{mM}$, and cells harvested after a $1 \mathrm{~h}$ incubation at $37^{\circ} \mathrm{C}$. The table combines results of two experiments in two different cystinotic cell lines. Control value for DTT and cystamine, $7.15 \mathrm{nmol} / \mathrm{mg}$ cell protein; control value, $3.73 \mathrm{nmol} / \mathrm{mg}$ cell protein for other compounds. ‡ Cell-free chemical reaction between L-cystine and $1 \mathrm{mM}$ concentration of reagents at pH 7.4 and $10 \mathrm{mM}$ potassium phosphate buffer at $37^{\circ} \mathrm{C}$. Incubation time was $30 \mathrm{~min}$. The reaction was stopped by addition of $5 \mathrm{mM}$ NEM. The remaining cystine was determined by cystine-binding protein assay. The table combines results of two experiments. The control value was $1.53 \mu \mathrm{M}$ cystine for cystamine, and $3.5 \mu \mathrm{M}$ cystine for all others.

ume is tripled. Treatment of these cells with cystamine produces only a $35 \%$ decline in label recovered as cystine, with no change in amount of label recovered as GSH and a threefold increase in label recovered as cysteine.

The discrepency between the amount of free cystine depletion produced by cysteamine and the cystamine in GSH-depleted fibroblasts is shown further with unlabeled cells in Table IIIB. $1 \mathrm{mM}$ cysteamine produces more than $90 \%$ depletion of intracellular nonprotein cystine in $1 \mathrm{~h}$, but the same concentration of cystamine produces only $60 \%$ depletion in the same time. In cells not depleted of GSH, identical cystine depletion is produced by cysteamine and cystamine (Fig. 2 and Table I).
The effect of $1 \mathrm{mM}$ cysteamine, cystamine, and GSH on the free cystine content of the granular fraction isolated from cystinotic fibroblasts is shown in Table IV. Cysteamine rapidly depletes the free cystine from these granules, but neither GSH nor cystamine do.

When cystamine is added to fibroblasts maintained in tissue culture, significant decreases occur in growth rates and cloning efficiency (Tables $\mathrm{V}$ and VI). At concentrations of cysteamine over $1 \mathrm{mM}$, cultures are found to be nonviable after approximately $72 \mathrm{~h}$.

Patient. Fig. 3 shows the response of peripheral leukocyte nonprotein cystine to the intravenous injection of $10 \mathrm{mg} / \mathrm{kg}$ of cysteamine. A rapid drop to $30 \%$ of control levels in $1 \mathrm{~h}$ is followed by a return toward the ini- 
TABLE II

Effect of C.ysteamine in Cystine-Deficient Medium on $\left.{ }^{35} S\right]$ Cystine-Labeled Compounds in Cystinotic and Normal Fibroblasts

\begin{tabular}{|c|c|c|c|c|c|c|}
\hline & \multicolumn{3}{|c|}{ Cystinotic } & \multicolumn{3}{|c|}{ Normal } \\
\hline & Cystine & Cys-NEM & GSH-NEM & Cystine & Cys-NEM & GSH-NEM \\
\hline & \multicolumn{3}{|c|}{$c p m / m g$ protein $\times 10^{6}$} & \multicolumn{3}{|c|}{ cpm/mg protein $\times 10^{-6}$} \\
\hline Control* $^{*}$ & 1.76 & 0.56 & 6.06 & $<0.01$ & 0.57 & 7.56 \\
\hline Cysteamine $\ddagger$ & $<0.01$ & 0.27 & 6.46 & $<0.01$ & 0.24 & 5.81 \\
\hline
\end{tabular}

* Four 100-mm tissue culture plates containing $7 \times 10^{5}$ cells/plate were incubated for $18 \mathrm{~h}$ in medium containing $32 \mathrm{mg} /$ liter of $\mathrm{L}-\left[{ }^{35} \mathrm{~S}\right]$ cystine (sp act $395 \mathrm{mCi} / \mathrm{mmol}$ ), and half were harvested by freezethaw technique.

† The remaining plates were washed four times in $4^{\circ} \mathrm{C}$ phosphate-buffered saline and replaced in cystinedeficient medium. Cysteamine was added to a final concentration of $1 \mathrm{mM}$ and cells were harvested after $2 \mathrm{~h}$ of incubation. See Methods section for details of compound separation and analysis.

tial value over the next $48 \mathrm{~h}$. No change in clinical status was observed during this period. The plasma concentration of free cystine fell approximately $50 \%$ during the 1 st $\mathrm{h}$ and returned to the control concentration by $24 \mathrm{~h}$.

The cumulative dose-response curve for oral cysteamine and leukocyte nonprotein cystine is shown in Fig. 4. Points represent measurements made on samples taken at the midpoint of doses given every $6 \mathrm{~h}$ when the patient had been on a given dose 48-72 h. At doses over $80 \mathrm{mg} / \mathrm{kg}$ per $24 \mathrm{~h}$, the patient's leukocyte nonprotein cystine level is in the range of that found in asymptomatic heterozygotes.

After gradually increasing cysteamine for $4 \mathrm{wk}$, the patient was discharged on $90 \mathrm{mg} / \mathrm{kg}$ per $24 \mathrm{~h}$ and followed for an additional $4 \mathrm{wk}$. Close monitoring of liver functions, blood count, electrolytes, renal function, and

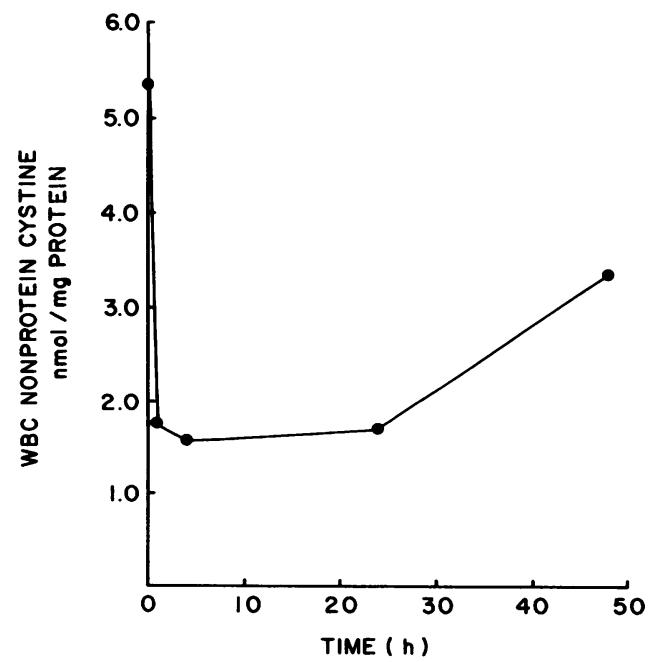

FIGURE 3 The effect of the intravenous injection of $10 \mathrm{mg}$ cysteamine $/ \mathrm{kg}$ body $\mathrm{wt}$ on the nonprotein cystine content of peripheral leukocytes. clinical status showed no adverse effects from this treatment. No significant change in serum creatinine concentration or creatinine clearance was noted. A $20 \%$ decline in blood urea nitrogen occurred, and probably reflects closer attention to salt and water balance than before the study (Table VII). No change in the keratopathy or osteodystrophy occurred during the study period.

Table VIII shows the 24-h urinary excretion values for total sulfur, total sulfate, cystine, and taurine, cor-

TABLE III

Effect of Cysteamine and Cystamine on GSH-Depleted Cystinotic Fibroblasts

\begin{tabular}{|c|c|c|c|}
\hline & Cystine & CYS-NEM & GSH-NEM \\
\hline & & \multicolumn{2}{|c|}{$\mathrm{cpm} / \mathrm{mg}$ protein $\times 10^{-6}$} \\
\hline \multicolumn{4}{|l|}{$A^{*}$} \\
\hline Control & 4.90 & 0.27 & 1.56 \\
\hline Cysteamine & 0.32 & 0.58 & 5.55 \\
\hline \multirow[t]{2}{*}{ Cystamine } & 2.80 & 0.90 & 1.40 \\
\hline & & \multicolumn{2}{|c|}{ nmol cystine $/ 10^{6}$ cells } \\
\hline \multicolumn{4}{|l|}{ B } \\
\hline Control & & \multicolumn{2}{|c|}{$1.21 \pm 0.04 \S$} \\
\hline Cysteamine & & \multicolumn{2}{|c|}{$0.04 \pm 0.01$} \\
\hline Cystamine & & \multicolumn{2}{|c|}{$0.46 \pm 0.02$} \\
\hline
\end{tabular}

* Cells were incubated for $22 \mathrm{~h}$ in $\mathrm{L}-\left[{ }^{36} \mathrm{~S}\right]$ cystine containing medium, rinsed four times in $4^{\circ} \mathrm{C}$ phosphate-buffered saline and replaced in cystine-deficient medium for an additional $22 \mathrm{~h}$. Cysteamine or cystamine was then added to plates to a final concentration of $1 \mathrm{mM}$, and cells were harvested by the freeze-thaw method after a $1-\mathrm{h}$ incubation at $37^{\circ} \mathrm{C}$.

$\ddagger$ Cells were incubated in cystine-deficient medium for $20 \mathrm{~h}$, and cysteamine or cystamine was then added to a final concentration of $1 \mathrm{mM}$ and incubated for $1 \mathrm{~h}$. Cells were harvested by trypsinization. Cystine content and protein were determined as in Methods.

$\S \mathrm{Mean} \pm \mathrm{SE}$. 
TABLE IV

Effect of Cysteamine, Cystamine, and GSH on Isolated Granular Fraction of Cystinotic Fibroblasts

\begin{tabular}{lcc}
\hline & Time & Cystine \\
\hline & min & $\begin{array}{c}\text { pmol/100 } \mu l \\
\text { granules }\end{array}$ \\
Control & 0 & 210 \\
& 30 & 190 \\
Cysteamine* & 30 & 25 \\
Cystamine* $^{*}$ & 30 & 213 \\
GSH* & 30 & 176 \\
\hline
\end{tabular}

* Reagent concentration was $1 \mathrm{mM}$. See Methods for details of granule fraction preparation and cystine assay.

related with the dosage level of cysteamine. Cysteamine caused a rise in the total sulfur excretion, paralleled by a rise in taurine excretion and inversely related to urinary cystine excretion. Total sulfate excretion did not change significantly, and thus the increase in sulfur excretion was composed of neutral sulfur.

After $4 \mathrm{wk}$ of $90 \mathrm{mg} / \mathrm{kg}$ per $24 \mathrm{~h}$, the patient experienced grand mal seizures unrelated to any definable etiology other than cysteamine. Institution of routine

\section{TABLE V}

Effect of Cystamine on Cloning Efficiency of Normal and Cystinotic Fibroblasts

\begin{tabular}{|c|c|c|c|c|}
\hline Cell strain & Passage & $\begin{array}{c}\text { Cystamine } \\
\text { concentration }\end{array}$ & $\begin{array}{c}\text { Cloning } \\
\text { efficiency }\end{array}$ & $\begin{array}{c}\text { Percent } \\
\text { of } \\
\text { control }\end{array}$ \\
\hline & & $\mu M$ & $\%$ & $\%$ \\
\hline \multicolumn{5}{|l|}{ Normal } \\
\hline \multirow[t]{5}{*}{ GM 38} & 23 & 0 & $10 \pm 1^{*}$ & 100 \\
\hline & & 0.1 & $14 \pm 4$ & 145 \\
\hline & & 1.0 & $17 \pm 3$ & 179 \\
\hline & & 10.0 & $2 \pm 2$ & 18 \\
\hline & & 100.0 & 0 & $\mathbf{0}$ \\
\hline \multirow[t]{5}{*}{ GM 75} & 19 & 0 & $12 \pm 4$ & 100 \\
\hline & & 0.1 & $11 \pm 6$ & 92 \\
\hline & & 1.0 & $8 \pm 4$ & 69 \\
\hline & & 10.0 & 0 & $\mathbf{0}$ \\
\hline & & 100.0 & $\mathbf{0}$ & 0 \\
\hline \multicolumn{5}{|l|}{ Cystinotic } \\
\hline \multirow[t]{5}{*}{$\mathbf{R B}$} & 12 & 0 & $36 \pm 10$ & 100 \\
\hline & & 0.1 & $43 \pm 6$ & 121 \\
\hline & & 1.0 & $37 \pm 7$ & 103 \\
\hline & & 10.0 & $6 \pm 5$ & 18 \\
\hline & & 100.0 & 0 & $\mathbf{0}$ \\
\hline \multirow[t]{5}{*}{ TJ } & 23 & 0 & $6 \pm 2$ & 100 \\
\hline & & 0.1 & $2 \pm 3$ & 37 \\
\hline & & 1.0 & $2 \pm 1$ & 37 \\
\hline & & 10.0 & 0 & $\mathbf{0}$ \\
\hline & & 100.0 & 0 & $\mathbf{0}$ \\
\hline
\end{tabular}

Triplicate 100-mM plates containing 100 cells/plate for each cell line and each cystamine concentration were placed initially in complete medium and changed to cystamine-containing medium after $24 \mathrm{~h}$. The medium was replenished on day 5 , and clones were counted on day 10.

* Mean \pm SD.

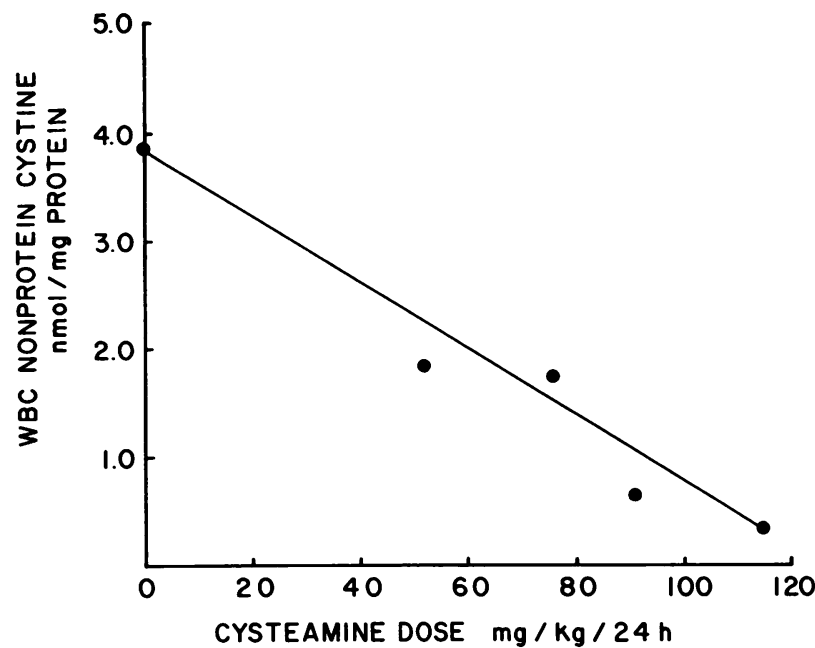

Figure 4 Cumulative dose-response curve for orally administered cysteamine and peripheral leukocyte nonprotein cystine content at progressively increasing dose levels. (See text for details).

seizure therapy and discontinuance of cysteamine produced cessation of seizures within $12 \mathrm{~h}$. Anticonvulsants were discontinued after $1 \mathrm{wk}$, and cysteamine was not reinstituted. Seizures have not recurred.

\section{DISCUSSION}

Previous interest in cysteamine has centered around its radioprotective effect and the potential physiological significance of its position as the S-terminal moiety of coenzyme A. Cysteamine is one of the most radioprotective compounds known (19). The protection is thought to result from scavenging of free radicals, either directly or via release of protein-bound GSH (19). An

TABLE VI

Effect of Cystamine on Apparent Growth Rate of Normal and Cystinotic Fibroblasts

\begin{tabular}{|c|c|c|c|c|}
\hline Cell strain & Passage & $\begin{array}{c}\text { Cystamine } \\
\text { concentration }\end{array}$ & $\begin{array}{l}\text { Doubling } \\
\text { time }\end{array}$ & $\begin{array}{c}\text { Percent } \\
\text { of } \\
\text { control }\end{array}$ \\
\hline & & $\mu M$ & $\boldsymbol{h}$ & $\%$ \\
\hline \multicolumn{5}{|l|}{ Normal } \\
\hline \multirow[t]{4}{*}{ GM 38} & 22 & $\mathbf{0}$ & 58 & 100 \\
\hline & & 1.0 & 61 & 105 \\
\hline & & 10.0 & 66 & 113 \\
\hline & & 100.0 & 120 & 207 \\
\hline \multicolumn{5}{|l|}{ Cystinotic } \\
\hline RB & 11 & $\mathbf{0}$ & 39 & 100 \\
\hline & & 1.0 & 39.6 & 98 \\
\hline & & 10.0 & 43 & 108 \\
\hline & & 100.0 & 102 & 257 \\
\hline
\end{tabular}

$1 \times 10^{5}$ cells were plated in triplicate in $60-\mathrm{mm}$ plates for each cell line and each cystamine concentration. After an initial $24 \mathrm{~h}$ in complete medium, the cells were placed in cystamine-containing medium and the cell number was determined on days 2 and 5 . The doubling time was calculated by assuming exponential growth between days 2 and 5 . 
TABLE VII

Clinical Parameters during Cysteamine Therapy

\begin{tabular}{|c|c|c|c|c|c|c|c|}
\hline & Control & Day 1 & Day 5 & Day 10 & Day 15 & Day 20 & Day $50^{*}$ \\
\hline Cysteamine, $m g / k g / 24 h$ & 0 & 45 & 67 & 90 & 110 & 90 & 90 \\
\hline $\mathrm{BUN}, \mathrm{mg} / 100 \mathrm{ml}$ & 145 & 133 & 115 & 102 & 128 & 124 & 111 \\
\hline Creatinine, $\mathrm{mg} / 100 \mathrm{ml}$ & 6.5 & 6.0 & 5.9 & 6.2 & 6.5 & 6.8 & 8.0 \\
\hline Creatinine clearance $\mathrm{ml} / \mathrm{min} / 1.73 \mathrm{~m}^{2}$ & 8.7 & 6.6 & 7.9 & 8.0 & 6.6 & 6.9 & 5.7 \\
\hline $\mathrm{Na}$, meq/liter & 142 & 146 & 143 & 144 & & 141 & 142 \\
\hline $\mathrm{K}$, meq/liter & 3.9 & 4.2 & 4.6 & 5.1 & & 3.8 & 4.3 \\
\hline $\mathrm{Cl}$, meq/liter & 97 & 97 & & & & 97 & 98 \\
\hline $\mathrm{HCO}_{3}, m g /$ liter & 20 & 25 & & 23 & & 22 & 22 \\
\hline $\mathrm{Ca}, m g / 100 m l$ & 9.9 & 9.6 & & 9.8 & & 10 & 10.4 \\
\hline $\mathrm{PO}_{4}, \mathrm{mg} / 100 \mathrm{ml}$ & 11.6 & 7.0 & & 6.2 & & 6.7 & 7.1 \\
\hline SGOT, IU & 20 & 21 & 13 & 31 & 24 & 23 & \\
\hline SGPT, IU & 13 & 13 & & 11 & & 20 & \\
\hline LDH, IU & 114 & 118 & 68 & & & & \\
\hline Alkaline phosphatase, IU & 67 & 66 & & 74 & 77 & 88 & \\
\hline White blood count & 5,600 & 3,700 & 4,400 & & & 5,000 & 7,300 \\
\hline Hematocrit & 20 & 19 & 17 & & & 18 & 12 \\
\hline Hemoglobin & 6.7 & 6.4 & 5.8 & & & 6.1 & 4.0 \\
\hline
\end{tabular}

* The patient was at home between days 20 and 50 and was clinically stable. She received a 1-U blood transfusion on day 50.

enzyme that liberates cysteamine from coenzyme $A$ has been reported in avian liver and hog kidney (20). Recently, studies have appeared demonstrating a protective effect of cysteamine against the hepatotoxic agents acetaminophen (17), bromobenzene (21), and phalloidine (22).

This report describes the rapid depletion of nonpro-

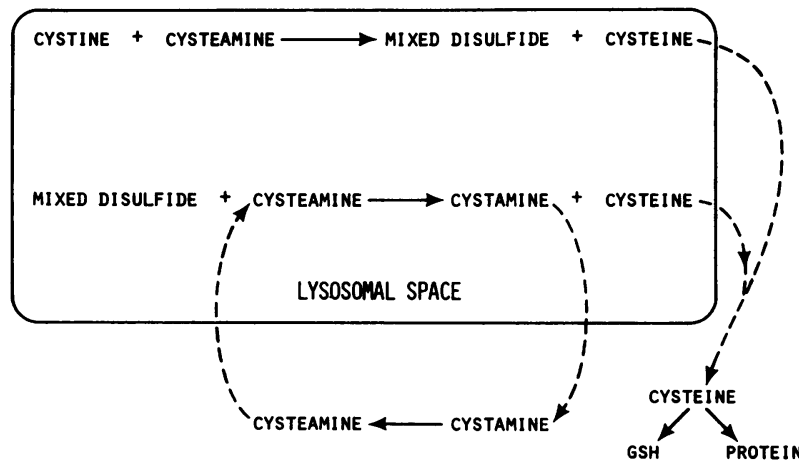

FIGURE 5 Proposed model for nonprotein cystine depletion from cystinotic fibroblasts produced by cysteamine. Cysteamine (mol wt 77) enters the lysosomal pool (see text) and reacts with cystine ( $\mathrm{mol}$ wt 240 ) to form cysteine (mol wt 120) and the mixed disulfide of cysteamine and cysteine (mol wt 196). Further reaction between cysteamine and the mixed disulfide leads to formation of cysteine and the disulfide, cystamine ( $\mathrm{mol}$ wt 152 ). All reaction products have mol wt of less than 200 daltons, and thus should freely diffuse from the lysosome. Cystamine is reduced to cysteamine in the cytoplasm by reaction with GSH (see Table IV). Cysteine enters normal biosynthetic pathways (Table IIIA). tein cystine produced by cysteamine in cystinotic fibroblasts and isolated granules in vitro and from peripheral leukocytes after oral and intravenous administration in vivo. Comparison with previously known methods of cystine depletion shows that cysteamine is more rapidly effective than DTT, ascorbic acid (6), or growth in a low-cystine medium (3). Cytopathic changes were not noted during the course of cystine depletion by cysteamine and cystamine, though significant reductions in growth rate and cloning efficiency occur in cells maintained in cystamine over longer periods of time (Tables $\mathrm{V}$ and VI).

The increase in label recovered from GSH in $\left[{ }^{35} \mathrm{~S}\right]-$ cystine-labeled cells treated with cysteamine, shown in

TABLE VIII

The Effect of Oral Cysteamine Therapy on Urinary Sulfur Excretion*

\begin{tabular}{clcrr}
\hline $\begin{array}{c}\text { Dose of } \\
\text { cysteamine }\end{array}$ & $\begin{array}{c}\text { Urinary } \\
\text { cystine }\end{array}$ & $\begin{array}{c}\text { Urinary } \\
\text { taurine }\end{array}$ & $\begin{array}{c}\text { Total } \\
\text { urinary } \\
\text { sulfur }\end{array}$ & \multicolumn{1}{c}{$\begin{array}{c}\text { Total } \\
\text { urinary } \\
\text { sulfate }\end{array}$} \\
\hline$m m o l / 24 h \ddagger$ & & \multicolumn{2}{c}{$m m o l / 24$} & $h \ddagger$ \\
0 & $0.28 \pm 0.05 \S$ & $0.02 \pm 0.01$ & $10.6 \pm 5.7$ & $8.7 \pm 5.5$ \\
7.0 & $0.18 \pm 0.04$ & $0.04 \pm 0.01$ & $12.3 \pm 1.6$ & $9.3 \pm 2.4$ \\
14.1 & $0.08 \pm 0.03$ & $0.24 \pm 0.09$ & $27.2 \pm 3.8$ & $10.4 \pm 2.8$ \\
17.6 & $0.08 \pm 0.01$ & $0.37 \pm 0.06$ & $30.9 \pm 2.2$ & $7.4 \pm 6.6$ \\
\hline
\end{tabular}

* The dietary sulfur intake other than cysteamine was estimated at $3 \mathrm{mmol} /$ day during this study.

$\ddagger$ All values are expressed in millimoles to facilitate comparison.

$\S$ Mean \pm SD. 
Table IIIA, indicates that the cystine released by this treatment can be utilized by the cell for GSH synthesis. This apparently occurs primarily within the cell, as the results are unaffected when the overlying medium is changed during the incubation or when the medium volume is increased.

Structural analogues of aminothiols lacking the amine moiety produce little or no free cystine depletion from cystinotic cells. Optimal depletion is produced by unsubstituted aminothiols, with primary and tertiary amines appearing equally effective. All of the sulfhydryl compounds tested in Table I are capable of reducing cystine in a cell-free chemical reaction; however, only relatively simple aminothiols produce marked intracellular nonprotein cystine depletion from cystinotic fibroblasts. Passage through two membranes (plasma and lysosomal) to reach the site of cystine storage may be critical in determining which compounds can deplete cystinotic fibroblasts of cystine, and this passage may be facilitated by the presence of the amine group.

Penicillamine is ineffective in removing intracellular free cystine under these conditions, reflecting its clinical ineffectiveness in patients with cystinosis (23). However, it is highly effective in removing the extracellular cystine accumulation (renal stones) in the unrelated disease, cystinuria (24).

Cystamine, a disulfide, would not be expected to react with the disulfide, cystine, unless cystamine were first reduced to the sulfhydryl form, cysteamine. Evidence for this reduction occurs in tissue slices (25) and in intact animals (26). The reaction probably is mediated in the cytosol by glutathione (27), either as a simple chemical reaction or via glutathione reductase $(28)$, and has been shown within mitochondria to result from reaction with reduced lipoic acid generated by the lipoamide dehydrogenase system (29). Inferential evidence that this occurs in fibroblasts is presented in Tables I, III, and IV, In intact cystinotic fibroblasts with normal intracellular GSH levels (30), cystamine and cysteamine are equally effective in producing intracellular nonprotein cystine depletion. In fibroblasts depleted of GSH, the major source of intracellular reductant (27), however, the ability of cystamine to lower the cystine concentration is decreased compared to cysteamine, which is unaffected. Furthermore, in systems lacking a soluble source of reducing power, i.e. isolated granules prepared by sonication and separated from the GSH-containing cytosol by centrifugation and resuspension in $0.25 \mathrm{M}$ sucrose (see Methods) and cystine in simple solution, cystamine does not lower the cystine concentration, while cysteamine continues to do so." The monosulfide, bis (2-amino-

\footnotetext{
- Preliminary studies utilizing ${ }^{36} \mathrm{~S}$-labeled cystamine and cysteamine have demonstrated intracellular reduction of cystamine to cysteamine in both normal and cystinotic
}

ethyl)sulfide, which cannot undergo disulfide exchange or simple disulfide reduction, is ineffective in lowering the cystine concentration both in solution and in fibroblasts. Its structural similarity to cystamine lends further support to the necessity for cystamine to undergo disulfide reduction before producing cystine depletion.

Diffusion through lysosomal membranes is restricted to molecules of molecular weight less than 200-230 daltons (31). Cystine accumulation in cystinotic lysosomes has been suggested to result in part from its relatively large molecular weight ( $\mathrm{mol} \mathrm{wt} \mathrm{240.3)} \mathrm{(32).} \mathrm{Cysteamine}$ (mol wt 77.15), cysteine ( $\mathrm{mol}$ wt 121.16), cystamine (mol wt 152.29), and the mixed disulfide of cysteine and cysteamine (mol wt 196.3) should all diffuse freely across such membranes.

In Fig. 5 a model is proposed that accounts for the observed depletion of cystine from cystinotic fibroblasts produced by cysteamine and cystamine. In this model, cysteamine enters the lysosome, perhaps facilitated by the amine group, and reacts with cystine, producing one molecule of mixed disulfide and one molecule of cysteine. Reaction of the mixed disulfide with cysteamine produces another molecule of cysteine and one molecule of cystamine. The cysteine can diffuse into the cytoplasm and be incorporated into GSH (Table III), while the cystamine so produced can be reduced back to cysteamine, as discussed above. As all reaction products have molecular weights under 200 , no net accumulation of any of these compounds should occur within the lysosome to replace the depleted cystine.

The objectives of this initial clinical study were: (a) to determine whether cysteamine produces cystine depletion from cystinotic tissues in vivo and, if so, the effective dose, $(b)$ to define side effects of this drug, and (c) to ascertain if improvement or stabilization of renal function could result from this treatment. The clinical trial was undertaken with the expectation that improvement of renal function was unlikely in a patient who already had end-stage renal failure. Although renal function was unchanged during the course of treatment, the study was terminated before any conclusion could be reached on the effect of cysteamine therapy on this parameter.

It is impossible to use renal cystine content as an index of cystine depletion because of the difficulty in obtaining multiple samples and because cystine is not uniformly distributed throughout this organ (33). Therefore, leukocytes were chosen as a readily accessible source of cystinotic tissue. Our data shows that cysteamine causes rapid cystine depletion from this tissue in vivo.

fibroblasts. Significant impurities in the commercially available preparations, however, have precluded inclusion of this data in the text. 
The patient's total urinary sulfur excretion increased roughly in proportion to the increases in oral cysteamine dose (Table VIII). Although the taurine excretion increased from 0.02 to $0.37 \mathrm{mmol} / \mathrm{day}$, this represents only a minute fraction of the urinary sulfate. The sulfate excretion remained relatively stable during this study. Thus neutral sulfur accounted for the bulk of the increase seen in total sulfur excretion. It is possible that the increase in neutral sulfur excretion was composed of cysteamine and its mixed disulfide with cysteine. Unfortunately, we are not yet able to identify and quantitate these compounds in physiological samples.

The metabolic fate of cysteamine has been studied in both experimental animals and man with conflicting results. After intravenous administration to dogs, $30 \%$ of the cysteamine was excreted unchanged in the urine (26). Oral administration of cysteamine to one adult human volunteer resulted in only $1 \%$ of the drug appearing unchanged in the urine $(34)$. The urinary cystine excretion fell from 0.28 to $0.08 \mathrm{mmol} /$ day during this study. It is possible that this was due to a fall in plasma cystine concentration resulting from formation of the cysteamine-cysteine mixed disulfide in plasma. A similar reaction occurs in cystinuric patients treated with D-penicillamine. In these patients the plasma and urinary cystine concentration decreases as the mixed disulfide of penicillamine and cysteine appears (35). Difficulty in enforcing stringent dietary regulations in an anorectic child and lack of quantitation of fecal sulfur excretion precluded a more formal balance study in our patient.

It is also possible that significant amounts of cystine labilized by the action of cysteamine were utilized for GSH (Table III) or protein synthesis. Such a mechanism would not necessarily lead to an increase in sulfur excretion.

During this study adverse side effects were not observed in liver functions, hematological indices, or electrolyte balance. An episode of seizures caused us to terminate the study. Seizures have occurred in animals treated with high doses of cysteamine intravenously (36) and may be analogous to the seizures produced by pryidoxine depletion resulting from treatment with penicillamine (37) or depletion of gamma-aminobutyric acid levels, as has been demonstrated in rats treated with high doses of 3-mercaptopropionic acid (38).

In a patient with impaired renal function blood cysteamine levels may have risen progressively during treatment, and development of a clinically applicable method for measurement of blood levels of cysteamine, cystamine, and the mixed disulfide of cysteamine and cysteine would assist further clinical investigation of this compound. Because of this patient's advanced stage of renal disease, improvement in renal function was not ex- pected. Further clinical trials in cystinotic patients with better renal function are warranted if accompanied by careful monitoring of plasma drug concentrations.

\section{ACKNOWLEDGMENTS}

We thank Dr. Robert Fahey for suggesting this study; Dr. Robert Hull for performing the pharmaceutical preparations; Dr. David Worthen for performing the ophthalmologic evaluations; Mrs. Ocean Pellett and Miss Patricia Neal for their superb technical assistance; the staff of the Clinical Research Center, University Hospital, University of California Medical Center, San Diego, for excellent nursing care; and Mr. Steve Smith for performing the amino acid analyses. We also thank Miss Nancy Kollisch for her help in the initial stages of the study and Dr. Stanley A. Mendoza for his critical evaluation of the manuscript.

This investigation was supported by U. S. Public Health Service Grants GM 17702 and RR 00827, Grant 1-373 from The National Foundation, and VA Research Grant MRIS 3181 .

\section{REFERENCES}

1. Schulman, J. D., and K. H. Bradley. 1972. In vitro studies on cystinosis. In Cystinosis. J. D. Schulman, editor. U. S. Government Printing Office, Washington, D. C. 111-145.

2. Schneider, J. A., and J. E. Seegmiller. 1972. Cystinosis and The Fanconi Syndrome. In The Metabolic Basis of Inherited Disease. J. B. Stanbury, J. B. Wyngaarden, and D. S. Fredrickson, editors. McGraw-Hill Book Company, New York. 3rd edition. 1581-1604.

3. Schulman, J. D., and K. H. Bradley. 1971. Cystinosis: Therapeutic implications of in vitro studies of cultured fibroblasts. J. Pediatr. 78: 833-836.

4. Goldman, H., C. R. Scriver, K. Aaron, and L. Pinsky. 1970. Use of dithiothreitol to correct cystine storage in cultured cystinotic fibroblasts. Lancet. 1: 811-812.

5. Aaron, K., H. Goldman, and C. R. Scriver. 1971. Cystinosis; new observations: 1. Adolescent (Type III) form. 2. Correction of phenotypes in vitro with dithiothreitol. In Inherited Disorders of Sulphur Metabolism. N. A. J. Carson and D. N. Raine, editors. Williams \& Wilkins Co., Baltimore, Md. 150-161.

6. Kroll, W. A., and J. A. Schneider. 1974. Decrease in free cystine content of cultured cystinotic fibroblasts by ascorbic acid. Science (Wash. D. C.). 86: 1040-1042.

7. Goldman, H., D. DePape-Brigger, E. Delvin, and C. R Scriver. 1974. Long-term use of oral dithiothreitol (DTT) in nephropathic cystinosis. Clin. Res. 22: 740A. (Abstr.).

8. Oshima, R. G., R. C. Willis, C. E. Furlong, and J. A. Schneider. 1974. Binding assays for amino acids. The utilization of a cystine binding protein from Escherichia coli for the determination of acid-soluble cystine in small physiological samples. J. Biol. Chem. 249: 60336039.

9. Kroll, W. A., F. L. A. Becker, and J. A. Schneider. 1974. Measurement of intracellular amino acids in cultured skin fibroblasts. The effect of storage on cystine recovery and evaluation of three methods of cell preparation. Biochem. Med. 10: 368-373.

10. Dulbecco, R., and M. Vogt. 1954. Plaque formation and isolation of pure lines with poliomyelitis viruses. J. Exp. Med. 99 : 167-182.

11. Lowry, O. H., N. J. Rosebrough, A. L. Farr, and 
R. J. Randall. 1951. Protein measurement with the Folin phenol reagent. J. Biol. Chem. 193: 265-275.

12. Atfield, G. N., and C. J. O. R. Morris. 1961. Analytical separations by high-voltage paper electrophoresis. Amino acids in protein hydrolysates. Biochem. J. 81: 606-614.

13. Schneider, J. A., F. M. Rosenbloom, K. H. Bradley, and J. E. Seegmiller. 1967. Increased free-cystine content of fibroblasts cultured from patients with cystinosis. Biochem. Biophys. Res. Commun. 29: 527-531.

14. Poole, J. R., S. H. Mudd, E. B. Conerly, and W. A. Edwards. 1975. Homocystinuria due to cystathionine synthase deficiency. Studies of nitrogen balance and sulfur excretion. J. Clin. Invest. 55: 1033-1048.

15. Lee, P. L. Y. 1974. Single-column system for accelerated amino acid analysis of physiological fluids using five lithium buffers. Biochem. Med. 10: 107-121.

16. Wong, V. G. 1972. The eye and cystinosis. In Cystinosis. J. D. Schulman, editor. U. S. Government Printing Office, Washington, D. C. 23-35.

17. Prescott, L. F., R. W. Newton, C. P. Swainson, N. Wright, A. R. W. Forrest, and H. Matthew. 1974. Successful treatment of severe paracetamol overdosage with cysteamine. Lancet. 1 : 588-592.

18. Oshima, R. G., W. R. Rhead, J. G. Thoene, and J. A. Schneider. 1976. Cystine metabolism in human fibroblasts: Comparison of normal, cystinotic and suspected $\gamma$-glutamyl cysteine synthetase deficient cells. J. Biol. Chem. In press.

19. Bacq, Z. M. 1965. Chemical Protection against Ionizing Radiation. Charles C Thomas, Publisher, Springfield, Ill. 16-25, 180-239.

20. Novelli, G. D., F. J. Schmetz, Jr., and N. O. Kaplan. 1954. Enzymatic degradation and resynthesis of coenzyme A. J. Biol. Chem. 206 : 533-545.

21. Mitchell, J. R., S. S. Thorgeirsson, W. Z. Potter, D. J. Jollow, and H. Keiser. 1974. Acetaminophen induced hepatic injury; protective role of glutathione in man and rationale for therapy. Clin. Pharmacol. Ther. 16: 676-684.

22. Floersheim, G. L. 1974. Rifampicin and cysteamine protect against the mushroom toxin phalloidin. Experientia (Basel). 30: 1310-1312.

23. Crawhall, J. C., P. S. Lietman, J. A. Schneider, and J. E. Seegmiller. 1968. Cystinosis. Plasma cystine and cysteine concentrations and the effect of D-Penicillamine and dietary treatment. Am. J. Med. 44: 330-339.

24. Crawhall, J. C. 1974. Cystinuria-diagnosis and treatment. In Heritable Disorders of Amino Acid Metabolism. W. L. Nyhan, editor. John Wiley \& Sons, Inc., New York. 593-617.
25. Pihl, A., L. Eldjarn, and J. Bremer. 1957. On the mode of action of $x$-ray protective agents. III. The enzymatic reduction of disulfides. J. Biol. Chem. 227: 339-345.

26. Mundy, R. L., M. H. Heiffer, and H. C. Leifheit. 1961. Blood and urine sulfhydryl and disulfide levels after large doses of beta-mercaptoethylamine (MEA) or cystamine. Radiat. Res. 14 : 421-425.

27. Jocelyn, P. C. 1972. Biochemistry of the SH group. Academic Press, Inc., New York. 10-11.

28. Tietze, F. 1972. Enzymic reduction of cystine and other disulfides. In Cystinosis. J. D. Schulman, editor. U. S. Government Printing Office, Washington, D. C. 147-197.

29. Skrede, S. 1968. The mechanism of disulphide reduction by mitochondria. Biochem. J. 108 : 693-699.

30. Schulman, J. D., J. A. Schneider, K. H. Bradley, and J. E. Seegmiller. 1972. Cystine, cysteine and glutathione metabolism in normal and cystinotic fibroblasts in vitro, and in cultured normal amniotic fluid cells. Clin. Chim. Acta. 37 : 53-58.

31. Ehrenreich, B. A., and Z. A. Cohn. 1969. The fate of peptides pinocytosed by macrophages in vitro. J. Exp. Med. 129: 227-245.

32. Schulman, J. D., and K. H. Bradley. 1970. Cystinosis: Selective induction of vacuolation in fibroblasts by $L-$ cysteine-D-penicillamine disulfide. Science (Wash. D.C.). 169: 595-597.

33. Schneider, J. A. 1974. Recent advances in cystinosis. In Heritable Disorders of Amino Acid Metabolism. W. L. Nyhan, editor. John Wiley \& Sons, Inc., New York. 618-637.

34. Eldjarn, L. 1954. The metabolism of cystamine and cysteamine. Scand. J. Clin. Lab. Invest. 6(Suppl. 13) : 49-60.

35. Crawhall, J. C., and C. J. Thompson. 1965. Cystinuria: Effect of D-penicillamine on plasma and urinary cystine concentrations. Science (Wash. D. C.). 147: 1459-1460.

36. Mundy, R. L., and M. H. Heiffer. 1960. The pharmacology of radio protectant chemicals. General pharmacology of $\beta$-mercaptoethylamine. Radiatr. Res. 13: 381394.

37. Tomono, I., M. Abe, and M. Matsuda. 1973. Effect of penicillamine (a vitamin $B_{6}$ antagonist) on pyridoxal enzymes. J. Biochem. $74: 587-592$.

38. de Lores-Arnaiz, G. R., M. A. de Canal, B. Robiolo, and M. M. de Pacheco. 1973. The effect of the convulsant 3-mercaptopropionic acid on enzymes of the $\boldsymbol{\gamma}$ aminobutyrate system in the rat cerebral cortex. $J$. Neurochem. 21 : 615-623. 